\title{
Nanosized carbon black as synergist in PP/POE-MA/IFR system for simultaneously improving thermal, electrical and mechanical properties
}

\author{
Xin Wen $^{1}$ (D) Karolina Szymańska ${ }^{1} \cdot$ Xuecheng Chen $^{1} \cdot$ Ewa Mijowska $^{1}$
}

Received: 9 January 2019/Accepted: 9 June 2019/Published online: 18 June 2019

(c) The Author(s) 2019

\begin{abstract}
Nanosized carbon black (CB) was introduced into polypropylene/maleic anhydride-grafted polyolefin elastomer/intumescent flame retardant (PP/POE-MA/IFR) system to investigate the effect of nanofiller as synergist on thermal, electrical and mechanical properties of polymer composites. With 5 mass\% CB into PP/POE-MA/IFR system (POFC5), the $T_{\text {max }}$ (corresponded to the temperature at the maximum mass loss rate) under air was increased by $122.4{ }^{\circ} \mathrm{C}$; its limited oxygen index was as high as 31.4\%; its vertical burning rating (UL-94) reached $V 0$, and the peak value of heat release rate was decreased to only $19 \%$ of neat PP in cone calorimeter testing. Moreover, PP composites exhibited good electrical conductivity with more than 1.6 mass $\% \mathrm{CB}$, which is a low loading level to reach the critical percolation concentration. In addition, a good balance on stiffness and toughness of PP composites was achieved; especially, Young's moduli and impact strength of POFC5 were increased to 1.26 and 2.5 times in comparison with that of neat PP, respectively. These results indicated that $\mathrm{CB}$ was an effective synergist in multi-component PP composites to simultaneously improve thermal, electrical and mechanical properties.
\end{abstract}

Keywords Carbon black · Flame retardancy · Mechanical properties · Polypropylene

\section{Introduction}

Polypropylene (PP), as one of the largely produced and consumed polymer materials, has broad applications in cars, furniture, insulation and architectural materials [1, 2]. However, some deficiencies of PP, such as unsatisfactory thermal stability, flammability and inherent brittleness at low temperature, restrict its wide usage in various fields $[3,4]$.

Intumescent flame retardants (IFRs), as a kind of halogen-free flame retardant, has attracted lots of interest due to their advantages on environment-friendly, low smoke production and non-toxicity [5-9]. So far, much excellent work has been done on using IFRs to improve the flame

Xin Wen

Xin.Wen@zut.edu.pl; hgwenxin@126.com

1 Nanomaterials Physicochemistry Department, Faculty of Chemical Technology and Engineering, West Pomeranian University of Technology in Szczecin, Al. Piastów 45, 70-311 Szczecin, Poland retardancy of PP $[10,11]$. Generally to achieve high level of flame retardancy, the required IFR loading in PP system was more than 30 mass $\%$ due to their low flame retardancy efficiency. As a result, such large amount of IFRs resulted in serious deteriorated mechanical performances of PP [12]. Thus, it is really a great challenge to fabricate PP composites with a synchronous improvement on flame retardancy and mechanical performances.

To improve comprehensive performances of PP/IFRs system, one feasible way is to incorporate nanofillers as synergists. For example, many types of inorganic nanoparticles have been used, including clay [13, 14], zeolite [15], carbon nanotube [16], graphene [17], layered double hydroxide (LDH) [18], silica [16], nano-aluminum hydroxide [19], metal oxides [20, 21] and other nanofillers [22-25]. Zeng et al. [14] added 2 mass\% phosphoruscontaining montmorillonite (P-MMT) into PP/IFRs system (the total content of flame retardant was 25 mass \%). The LOI of PP composites was increased to $32.5 \%$, and the UL94 rating was enhanced to $V 0$. Nie et al. [16] reported that only 0.3 mass \% of nickel phosphate nanotubes (NiPO-NT) 
could obviously improve the flame retardant and thermal properties of PP/IFR composites. Yang group [26] found that with the addition of 0.1 mass $\% \mathrm{Bi}_{2} \mathrm{O}_{3}$ and 1 mass $\%$ nanoclay into PP/25 mass\% IFRs system, the LOI reached $31.5 \%$, and the UL-94 passed V0. More importantly, the synergistic system exhibited better mechanical properties than PP/IFRs composites, which was attributed to the enhancement effect of nanofillers and the increase in flame retardancy efficiency.

Nanosized carbon black (CB) is one of the most widely used nanofillers because of its abundant source, low density, permanent conductivity and low cost. In our previous work [25], the addition of CB into PP displayed not only dramatic enhancement on thermal stability, but also significant improvement on flame retardancy with a marked reduction in peak heat release rate (PHRR) and increase in LOI value. In the present work, CB was selected as synergist of IFRs to improve thermal stability and flame retardancy of PP. Meanwhile, maleic anhydride-grafted polyolefin elastomer (POE-MA) was employed as toughening agent and compatibilizer to optimize the mechanical properties of PP/IFRs/CB system. A good balance on flame retardancy and mechanical performances was achieved due to the synergistic effect of CB, IFRs and POE-MA. Furthermore, the effect of $\mathrm{CB}$ on the thermal stability and electrical conductivity of PP composites were also investigated.

\section{Experimental}

\section{Materials}

Polypropylene (PP, isotactic, $M_{\mathrm{w}}=28.9 \times 10^{4} \mathrm{~g} \mathrm{~mol}^{-1}$, polydispersity $=3.45$ ) powder was supplied by Daqing Petrochemical Co., Ltd. Carbon black (CB, purity: > 99\%) was purchased from Linzi Qishun Chemical Co., Shandong, with the original particle diameter of $17 \mathrm{~nm}$. Maleic anhydride-grafted polyolefin elastomer (POE-MA) was supplied by Shenyang Siwei High Polymer Plastic Co., Ltd (Shenyang, China). Its MA grafting ratio was $0.96 \%$. Ammonium polyphosphate (APP) was purchased from Zhenjiang Xingxing Flame retardant Co., Ltd (Zhenjiang, China). Pentaerythritol (PER) was provided by Fuyu Fine Chemical Co., Ltd (Tianjin, China).

\section{Preparation of PP composites}

The PP composites were prepared via melt compounding at $180{ }^{\circ} \mathrm{C}$ in a batch intensive mixer (Haake Rheomix 600, Karlsruhe, Germany) with a rotor speed of $60 \mathrm{rpm}$; the mixing time was $8 \mathrm{~min}$ for each sample. The composition of these composites is listed in Table 1. The PP composites
Table 1 The composition of POF composites with different $\mathrm{CB}$ content

\begin{tabular}{lllcl}
\hline Samples & \multicolumn{2}{l}{ Comp. mass\% } & \\
\cline { 2 - 5 } & PP & POE-MA & IFRs & CB \\
\hline PP & 100 & 0 & 0 & 0 \\
POF & 72 & 8 & 20 & 0 \\
POFC0.5 & 71.5 & 8 & 20 & 0.5 \\
POFC1 & 71 & 8 & 20 & 1 \\
POFC3 & 69 & 8 & 20 & 3 \\
POFC5 & 67 & 8 & 20 & 5 \\
\hline
\end{tabular}

contained 8 mass $\%$ POE-MA and 20 mass\% IFRs (APP/ PER $=3 / 1$ by mass), and the CB content changed from 0.5 to 5 mass $\%$ in the composites. For convenience, the resultant samples were designated as POFCx. Here, P, O, F and $\mathrm{C}$ denote polypropylene, POE-MA, IFR and CB, respectively; while $\mathrm{x}$ denotes the mass percentage of $\mathrm{CB}$ in the PP composites.

\section{Characterization}

Thermogravimetric analysis (TGA) was performed on a TA STD Q600 thermal analyzer. The PP samples with mass $6.0 \pm 0.2 \mathrm{mg}$ were heated from room temperature to $600{ }^{\circ} \mathrm{C}$ at $10{ }^{\circ} \mathrm{C} \mathrm{min}{ }^{-1}$ under air.

The morphologies of the fracture surfaces were examined by XL30 ESEM FEG (FEI Co.).The samples were frozen well in liquid nitrogen and quickly broken off to obtain a random brittle-fractured surface. A layer of gold was sputter-coated uniformly over all the fractured surfaces before SEM observations.

The limited oxygen index (LOI) was measured on a JF-3 oxygen index meter (Jiangning, China) with sheet dimensions of $130 \times 6.5 \times 3.2 \mathrm{~mm}^{3}$, according to ISO45891984. The vertical burning testing was carried out according to UL-94 (ANSI/ASTMD635-77) with sheet dimensions of $125 \times 12.7 \times 3.2 \mathrm{~mm}^{3}$. Cone calorimeter tests were performed using an FTT, UK device according to ISO 5660 at an incident flux of $50 \mathrm{~kW} \mathrm{~m}{ }^{-2}$, and the size of specimens was $100 \mathrm{~mm} \times 100 \mathrm{~mm} \times 6.0 \mathrm{~mm}$; each sample was tested three times. The photographs of the residual chars after the cone calorimeter tests were collected by a digital camera.

The volume resistance of PP samples was measured by ZC36 high-resistance meter (Shanghai Precision and Scientific Company, China) at room temperature. Minimum of five tests were performed for each specimen, and the average data were reported.

Uniaxial tensile tests were performed with an Instron 1121 testing machine (Canton, MA). Specimens 
$(20 \mathrm{~mm} \times 4 \mathrm{~mm} \times 1 \mathrm{~mm})$ were cut from the above compression molded sheet with a dumbbell shape. The measurements were conducted at a crosshead speed of $20 \mathrm{~mm} \mathrm{~min}^{-1}$ at room temperature. The V-notched specimens $(55 \mathrm{~mm} \times 6 \mathrm{~mm} \times 4 \mathrm{~mm})$ were performed to measure the impact strength according to GB1843-93 procedures using an impact testing machine (CEAST, China). All tests were carried out at room temperature and $50 \%$ relative humidity. At least five runs for each sample were measured and averaged as results.

\section{Results and discussion}

\section{Thermal stability}

The influence of $\mathrm{CB}$ content on the thermal stability of PP/ POE-MA/IFRs composites in air was investigated by TGA. As shown in Fig. 1a, with the increase in CB content, the thermal decomposition curves shifted significantly to a higher temperature range, indicating an improvement on thermal stability. According to the data listed in Table 2 , both $T_{5 \text { mass } \%}$ and $T_{10 \text { mass } \%}$ (corresponding to 5 and 10 mass $\%$ mass loss, respectively) of PP gradually increased with the addition of CB content, which was attributed to the trap peroxyl radicals effect of $\mathrm{CB}$ on inhibiting the decomposition of PP matrix on onset stage [25, 27, 28].

To evaluate the thermal stability of polymer materials, another important characteristic parameter is the temperature corresponding to the maximum rate of mass loss $\left(T_{\max }\right)$, which is defined as the peak value of the first derivative TGA curve as a function of temperature. As shown in Fig. 1b, the $T_{\max }$ was derived from several peaks due to the multi-component of PP composites. The detailed data were also summarized in Table 2. The peak near to

(a)

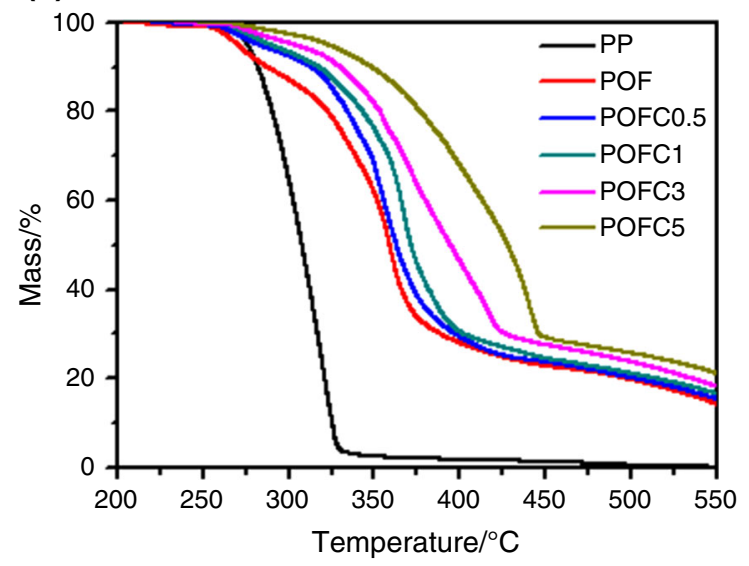

Table 2 Thermal decomposition properties of PP samples in air

\begin{tabular}{|c|c|c|c|c|c|}
\hline \multirow[t]{2}{*}{ Samples } & \multirow{2}{*}{$\begin{array}{l}T_{5 \text { mass } \% /} / \\
{ }^{\circ} \mathrm{C}\end{array}$} & \multirow{2}{*}{$\begin{array}{l}T_{10 \text { mass } \%} / \\
{ }^{\circ} \mathrm{C}\end{array}$} & \multicolumn{3}{|l|}{$T_{\max } /{ }^{\circ} \mathrm{C}$} \\
\hline & & & $\begin{array}{l}T_{\text {peak } 1} / \\
{ }^{\circ} \mathrm{C}\end{array}$ & $\begin{array}{l}T_{\text {peak } 2 /} / \\
{ }^{\circ} \mathrm{C}\end{array}$ & $\begin{array}{l}T_{\text {peak } 3 /} \\
{ }^{\circ} \mathrm{C}\end{array}$ \\
\hline PP & 275.8 & 281.5 & - & 320.1 & - \\
\hline POF & 260.2 & 275.8 & 271.9 & 353.7 & - \\
\hline POFC0.5 & 266.3 & 296.1 & 271.9 & 360.5 & - \\
\hline POFC1 & 272.4 & 301.6 & 272.3 & 370.4 & - \\
\hline POFC3 & 277.9 & 317.2 & 272.2 & 371.0 & 421.9 \\
\hline POFC5 & 291.4 & 334.2 & 272.0 & 373.4 & 442.5 \\
\hline
\end{tabular}

$272{ }^{\circ} \mathrm{C}\left(T_{\text {peak } 1}\right)$ was assigned to the thermal decomposition of PER due to its relatively low molecular weight. With the increase in CB content from 0.5 to 1 mass $\%$, the decomposition peak of PP $\left(T_{\text {peak2 }}\right)$ correspondingly shifted from 360.5 to $370.4{ }^{\circ} \mathrm{C}$, which is much higher than $320.1{ }^{\circ} \mathrm{C}$ for that of neat $\mathrm{PP}$, suggesting the positive effect of $\mathrm{CB}$ on improving the thermal stability of PP. More interestingly, with further increase in the CB content, the peak density of $T_{\text {peak2 }}$ gradually became weaker, and meanwhile, there presented another new peak at higher temperature $\left(T_{\text {peak } 3}\right)$. When 5 mass\% of CB was added into POF system, the peak of $T_{\text {peak2 }}$ at $370{ }^{\circ} \mathrm{C}$ areas was almost disappeared, and the new $T_{\text {peak3 }}$ was present at $442.5{ }^{\circ} \mathrm{C}$, which was 122.4 and $88.8^{\circ} \mathrm{C}$ higher than the decomposition peak of neat PP and POF, respectively. These results indicated that the oxidative dehydrogenation reaction of $\mathrm{PP}$ was effectively inhibited by the addition of $\mathrm{CB}$, resulting in a dramatic improvement on its thermal stability.

\section{Flame retardancy}

LOI and UL-94 tests were firstly employed to evaluate the flame retardancy of PP samples, which are useful methods

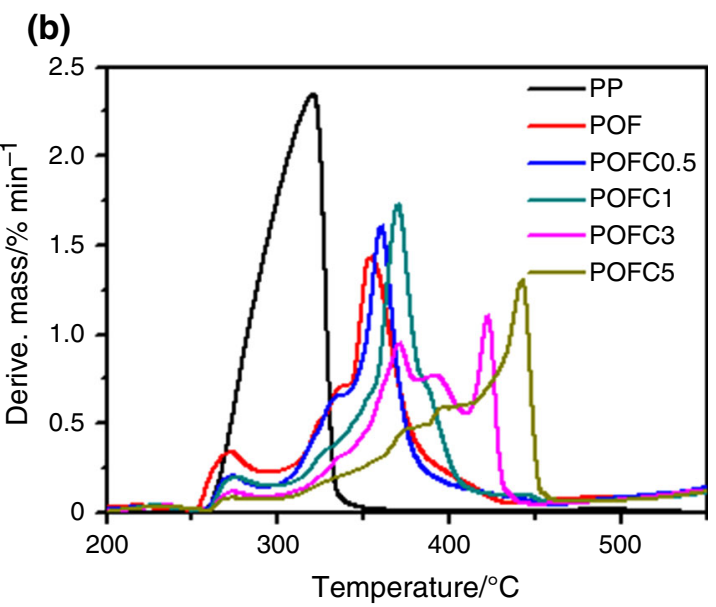

Fig. 1 TGA and DTG curves for PP samples in air. a TGA; b DTG 
to analyze the combustion behavior of composite materials [29]. As listed in Table 3, it could be seen that the LOI value of neat PP was only $18.0 \%$. With the addition of 20 mass\% IFRs into PP, the LOI value of POF reached $26.0 \%$, but it was still no-ratting in UL-94 with serious dripping. In contrast, after the addition of only 0.5 mass $\%$ $\mathrm{CB}$ into POF, the LOI increased to 27.2, and the dripping was effectively inhibited. When the CB content was up to 3 mass \%, the LOI was 29.7 and the UL-94 rating was V1. After further increase in the loading of CB to 5 mass\%, the LOI of POFC5 could reach $31.4 \%$, and its UL-94 rating could pass $V 0$. The above results suggested that the optimal loading of CB in POF system was 5 mass\%, which exhibited the best synergistic effect with IFRs to improve the flame retardancy of PP.

To visually show the inhibiting dripping effect of $\mathrm{CB}$, the morphology of neat PP and PP composites after LOI testing was detected. As shown in Fig. 2a, the molten drip of PP was eye-catching. For POF in Fig. 2b, some black char was present, but its drip was still visible. Differently, there remained more amount of char from POFC3 and POFC5 (Fig. 2c, d). More importantly, their char was

Table 3 Combustion parameters of PP samples from LOI and UL-94 tests

\begin{tabular}{llll}
\hline Samples & LOI/\% & \multicolumn{2}{l}{ UL-94 at 3.2 mm } \\
\cline { 3 - 4 } & & Rating & Dripping \\
\hline PP & $18.0 \pm 0.5$ & Fail & Yes \\
POF & $26.0 \pm 0.4$ & Fail & Yes \\
POFC0.5 & $27.2 \pm 0.2$ & Fail & No \\
POFC1 & $28.0 \pm 0.4$ & Fail & No \\
POFC3 & $29.7 \pm 0.3$ & $V 1$ & No \\
POFC5 & $31.4 \pm 0.3$ & $V 0$ & No \\
\hline
\end{tabular}

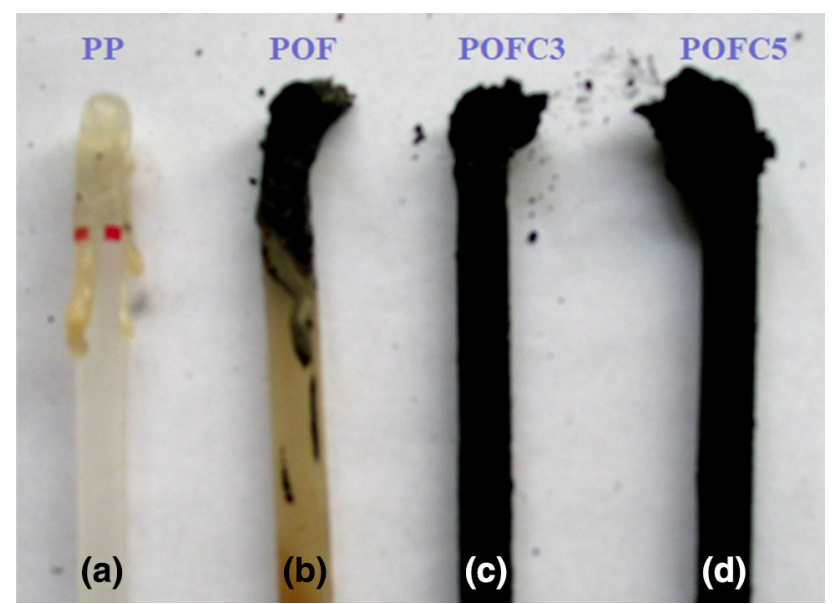

Fig. 2 The photographs of PP samples after LOI testing. a neat PP; b $\mathrm{POF}$, c POFC3; d POFC5 stable and self-standing with no molten drip. This clearly demonstrates that $\mathrm{CB}$ played an important role on increasing the melt strength of PP, leading to the increase in quantity and quality of residual char.

The flame retardancy of PP samples was further evaluated by cone calorimeter test, which is considered to be an effective tool in evaluating fire performance and can provide a wealth of information on the combustion behavior [30], such as time to ignition (TTI), peak heat release rate (PHRR) and total heat release (THR). Figure 3 shows the heat release rate (HRR) curves of PP and its composites, and its detailed combustion parameters are recorded in Table 4. With the addition of 20 mass\% IFRs, the TTI became shorter, which suggested that POF was easier to be ignited than PP itself. However, with the increase of $\mathrm{CB}$ content into POF, the TTI values gradually became longer, implying that the presence of $\mathrm{CB}$ had positive effect on prolonging the onset combustion process of PP. Moreover, in comparison with neat PP, POF displayed a great decrease in PHRR, and the decrease trend became more significant by incorporation of CB. Exactly, the value of PHRR for POFC5 reduced to $244 \mathrm{~kW} \mathrm{~m}^{-2}$, which was only $19 \%$ of that for neat PP $\left(1261 \mathrm{~kW} \mathrm{~m}^{-2}\right)$. More specially, the HRR curve of POFC5 kept almost flat with a small value for a long time after its PHRR, which generally represented a lower fire spread rate until the combustion finished. Similar to PHRR, the THR also decreased with the addition of $20 \%$ IFRs, and it further decreased with the increase of CB loading into POF (Table 4).

The mass loss rate (MLR) of a polymer during combustion is also helpful to evaluate its flammability properties. Generally, the slope of MLR curve is assumed as representing the combustion rate of polymers. Figure 4 shows the change of normalized mass loss of PP samples with combustion time. It was apparent that adding IFRs into PP matrix led to a dramatic decrease of MLR in the later stage of combustion. Furthermore, the slope of POFC

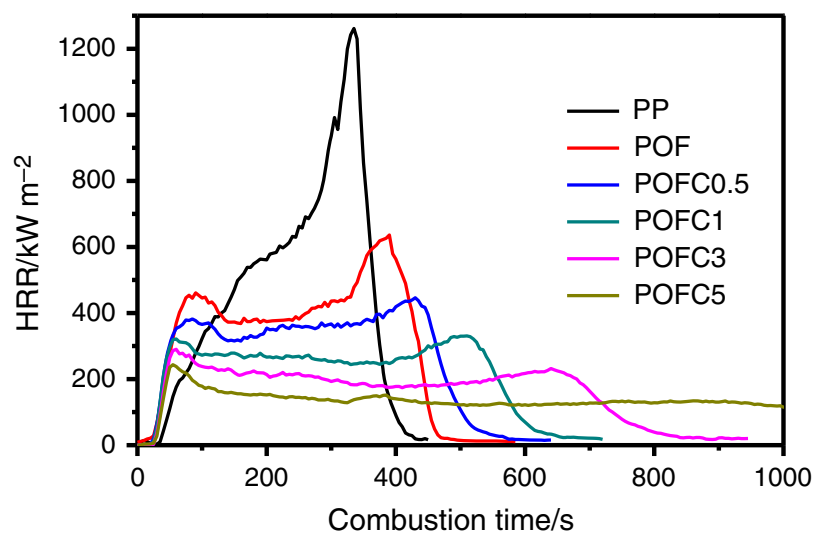

Fig. 3 Heat release rate curves of neat PP and its composites from cone calorimeter testing 
Table 4 Combustion parameters of neat PP and its composites from cone calorimeter testing

\begin{tabular}{llrcl}
\hline Samples & \multicolumn{1}{l}{ TTI/s } & \multicolumn{1}{c}{$t_{\mathrm{PHRR}} / \mathrm{s}$} & PHRR/kW m & THR/MJ m \\
\hline PP & $30 \pm 2$ & $335 \pm 5$ & $1261 \pm 35$ & $208 \pm 8$ \\
POF & $21 \pm 4$ & $395 \pm 7$ & $636 \pm 26$ & $176 \pm 5$ \\
POFC0.5 & $22 \pm 3$ & $430 \pm 5$ & $446 \pm 23$ & $167 \pm 6$ \\
POFC1 & $23 \pm 3$ & $510 \pm 8$ & $331 \pm 16$ & $153 \pm 7$ \\
POFC3 & $25 \pm 2$ & $55 \pm 6$ & $290 \pm 20$ & $150 \pm 6$ \\
POFC5 & $26 \pm 4$ & $50 \pm 6$ & $244 \pm 15$ & $149 \pm 8$ \\
\hline
\end{tabular}

samples became much smaller with the increase in CB content, which indicated that $\mathrm{CB}$ played an important role on delaying the decomposition and combustion of $\mathrm{PP}$ matrix.

To study the enhancement mechanism of $\mathrm{CB}$ in $\mathrm{POF}$ system, the structure of the residual chars after cone calorimeter testing was investigated. Figure 5 exhibits the photographs of the residual chars from neat PP, POF and POFC samples. For neat PP, no char was left due to its inherent flammability with whole aliphatic hydrocarbon structure (Fig. 5a). In the cases of POF, a continuous carbon layer was formed, but it was thin and contained big holes on its surface (Fig. 5b). With the combination of CB and IFRs, block-like black solids were present. With the increase in CB content, the char became more continuous and dense. Moreover, the size of linked carbon blocks became smaller (Fig. $5 \mathrm{c}-\mathrm{f}$ ), indicating higher strength and supporting capacity. The improved carbon layer could not only enhance the physical barrier effect to prevent oxygen diffusion and volatile products pervaporation, but also act as a thermal shield for energy feedback from the flame during combustion [31]. Therefore, the combination of IFRs and $\mathrm{CB}$ displayed a significant enhancement on thermal stability and flame retardancy of PP.

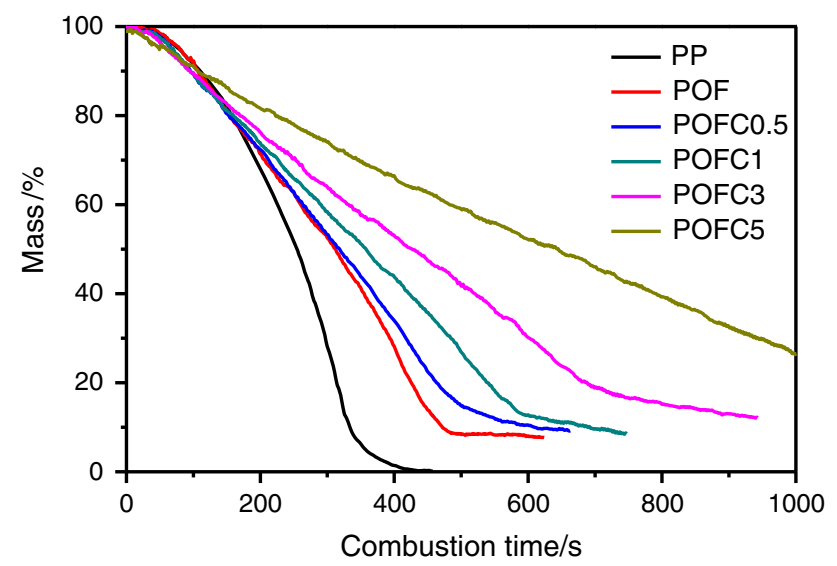

Fig. 4 Normalized mass loss curves of neat PP and its composites from cone calorimeter testing at an incident heat flux of $50 \mathrm{~kW} \mathrm{~m}^{-2}$

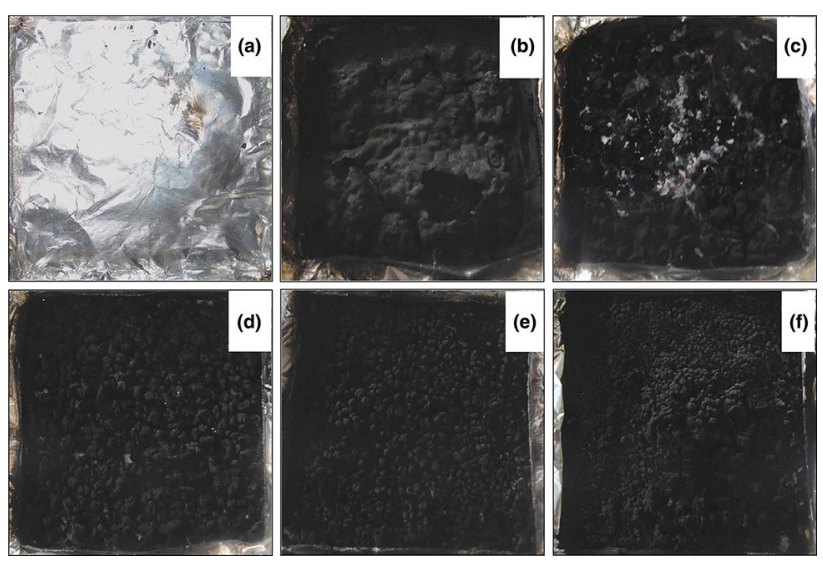

Fig. 5 Photographs of the residual chars: a neat PP; b POF; c POFC0.5; d POFC1; e POFC3; f POFC5

\section{Electrical conductivity}

Carbon-based conductive polymer composites have been widely used in a broad array of industrial and engineering fields. As one typical conductive nanoparticles, CB could form electrical network in polymer matrix once the filler loading reaches a critical percolation concentration. To exactly evaluate the critical CB concentration in our PP system, smaller concentration gradient between 1.0 mass $\%$ and 2.0 mass\% was selected. As shown in Fig. 6, the effect of $\mathrm{CB}$ content on electrical conductivity of PP composites was investigated. When the $\mathrm{CB}$ content was less than 1.4 mass \%, the values of volume resistivity for PP samples were as high as $10^{17} \Omega \mathrm{cm}$, indicating they were classed as insulating materials. Surprisingly, when the CB content reached 1.6 mass $\%$, the volume resistivity suddenly dropped to $10^{8} \Omega \mathrm{cm}$. With further increase of CB content up to 5 mass\%, the resistivity kept stably at this level. These results indicated that 1.6 mass\% was the critical percolation concentration in our POF system. In comparison with other carbon-based conductive nanoparticles, our data were superior or at least comparable to most reported results $[32,33]$. It is possibly attributed to our multi-phase system of PP composites, in which the selective distribution of conductive nanoparticles could have a sharp decrease in electrical resistivity to form conductive paths over a narrow conductive filler range [34, 35].

In polymer composites, the dispersion of fillers and matrix-filler interaction are the most important factors to determine their resultant performances; especially, the distribution of conductive nanoparticles greatly influences electrical conductivity [36]. As abovementioned, 1.6 mass \% corresponded to the critical percolation concentration of CB in our PP/POE-MA/IFR system; so the micrographs of fracture surfaces for POF and POFC1.6 were 


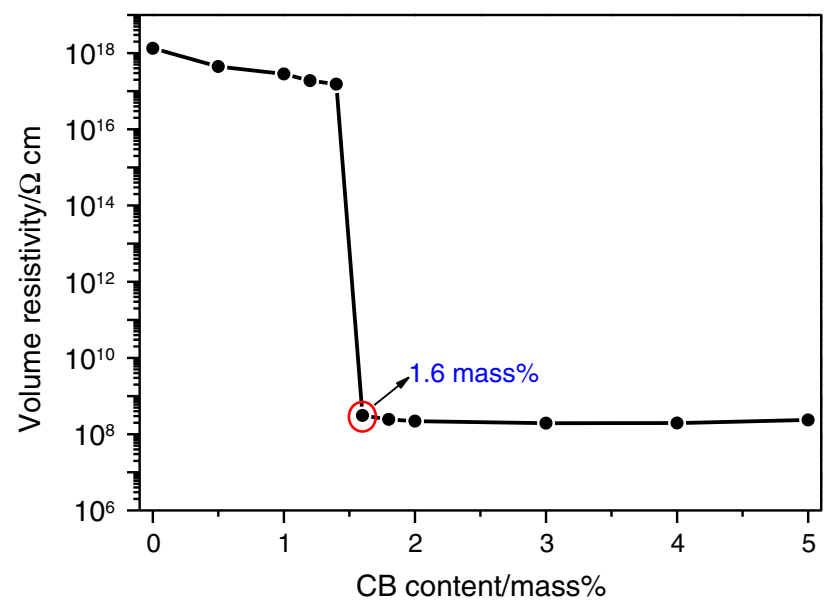

Fig. 6 Effect of CB content on electrical conductivity of POF system

compared in Fig. 7a-d. It was apparent that IFR particles were detected as irregular blocks in micron size (Fig. 7a), and they were adhered firmly to PP matrix without interfacial debonding (Fig. 7b with red circle). Similarly, as shown in Fig. 7c for POFC1.6, there was a good dispersion

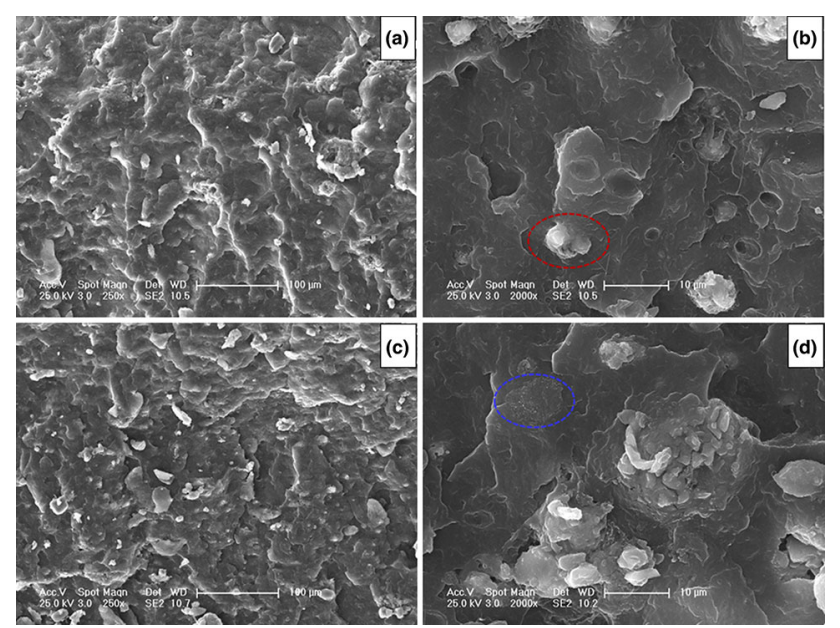

Fig. 7 FE-SEM micrographs of brittle-fractured surfaces for PP composites. a, b POF; c, d POFC1.6 for IFR particles and strong matrix-filler interaction. Specially, some aggregates of bright dots were present (Fig. 7d with blue circle), which was the adsorption of $\mathrm{CB}$ nanoparticles onto the POE-MA surfaces (the hydroxyl groups in $\mathrm{CB}$ could react with anhydride groups in POEMA). These results further indicated that selective distribution of $\mathrm{CB}$ resulted in low critical percolation concentration in our multi-phase PP composites.

\section{Mechanical properties}

It is well-known that the incorporation of flame retardant at high percentages into polymer matrices usually improves their flame retardancy at the expense of the mechanical properties. Considering the reinforcement of $\mathrm{CB}$ and the toughening effect of POE-MA, a balance on mechanical properties was expected, which is very attractive to academic and industrial communities.

The effect of CB on mechanical properties of POF was investigated by tensile and notched-impact tests. As shown in Table 5, the detailed data for Young's modulus, tensile strength, elongation at break and notched-impact strength are summarized. With the addition of 20 mass $\%$ IFR and 8 mass\% POE-MA into PP, Young's modulus and tensile strength of POF greatly decreased, but it kept relatively high value for elongation at break and its impact strength increased 1.8 times. With the increase in $\mathrm{CB}$ concentration from 0.5 to 5 mass\% in POFC composites, the values for Young's modulus and tensile strength as well as impact strength were gradually increased. For instance, Young's modulus of POFC5 reached $1.07 \mathrm{GPa}$, which is 1.26 times higher than that of neat PP; its tensile strength was more or less the same as neat $\mathrm{PP}$ due to the compromise of positive and negative effects of POE-MA and CB. Meanwhile, its impact strength was 2.5 times higher than the value of neat PP. Although the elongation at break decreased with the increase in CB loading, it was still kept more than $130 \%$. According to these results, a high balance on stiffness and toughness of PP composites was achieved. The enhancement mechanism may be attributed to two aspects: on one

Table 5 Mechanical properties for neat PP and its composites

\begin{tabular}{lllll}
\hline Samples & Young's modulus/GPa & Tensile strength/MPa & Elongation at break/\% & Notched-Impact strength/kJ m $^{-2}$ \\
\hline PP & $0.85 \pm 0.07$ & $35.16 \pm 0.92$ & $650 \pm 40$ & $2.20 \pm 0.22$ \\
POF & $0.74 \pm 0.08$ & $29.35 \pm 0.86$ & $420 \pm 36$ & $4.06 \pm 0.32$ \\
POFC0.5 & $0.76 \pm 0.06$ & $30.05 \pm 1.20$ & $406 \pm 28$ & $4.28 \pm 0.21$ \\
POFC1 & $0.81 \pm 0.09$ & $31.57 \pm 1.65$ & $312 \pm 30$ & $4.42 \pm 0.36$ \\
POFC3 & $0.89 \pm 0.08$ & $32.80 \pm 1.81$ & $215 \pm 24$ & $4.78 \pm 0.34$ \\
POFC5 & $1.07 \pm 0.09$ & $35.08 \pm 2.21$ & $132 \pm 27$ & $5.52 \pm 0.30$ \\
\hline
\end{tabular}


hand, as a toughening agent POE-MA could improve the toughness of PP, and meanwhile as an effective compatibilizer, it could enhance matrix-filler interaction [31, 37], and on the other hand, $\mathrm{CB}$ as rigid nanoparticles could improve the modulus and strength on the help of compatibilizer. Consequently, the comprehensive effect of POEMA and CB resulted in the improvement on mechanical properties of PP.

\section{Conclusions}

Multi-component PP composites were prepared by incorporation of IFRs, POE-MA and CB nanofillers to improve its comprehensive performances. $\mathrm{CB}$ as synergist in $\mathrm{PP} /$ POE-MA/IFR system was effective to simultaneously improve thermal stability, flame retardancy, electrical conductivity and balanced mechanical properties. The POFC5 (with 5 mass\% CB into PP/POE-MA/IFR) exhibited an increase on $T_{\max }$ under air by $122.4{ }^{\circ} \mathrm{C}$; its LOI was 31.4\%; UL-94 reached $V 0$ rating and the PHRR decreased to only $19 \%$ of neat PP in cone calorimeter testing. The dramatically improved thermal stability and flame retardancy were attributed to the synergistic effect of IFRs and $\mathrm{CB}$, which could effectively inhibit oxidative dehydrogenation reaction of $\mathrm{PP}$ and facilitate the formation of a better dense and continuous carbon protective layer during combustion. Meanwhile, the critical percolation concentration of CB in PP system was only 1.6 mass\%, which promoted the transformation from insulator to conductive material. In addition, a good balance on mechanical performances was achieved via the combination of POE-MA and $\mathrm{CB}$, including outstanding toughness and high stiffness. In summary, CB was an effective synergist on improving the comprehensive properties in multi-component PP composite system. This work not only provides a facile method to prepare multifunctional and high-performance polymer composites, but also is favorable to its multi-domain applications.

Acknowledgements This work is supported by the National Science Centre Poland OPUS UMO-2018/29/B/ST8/01265.

Open Access This article is distributed under the terms of the Creative Commons Attribution 4.0 International License (http://creative commons.org/licenses/by/4.0/), which permits unrestricted use, distribution, and reproduction in any medium, provided you give appropriate credit to the original author(s) and the source, provide a link to the Creative Commons license, and indicate if changes were made.

\section{References}

1. Xiao D, Li Z, De Juan S, Gohs U, Wagenknecht U, Voit B, et al. Preparation, fire behavior and thermal stability of a novel flame retardant polypropylene system. J Therm Anal Calorim. 2016;125(1):321-9.

2. Yang HF, Ye L, Gong J, Li MG, Jiang ZW, Wen X, et al. Simultaneously improving the mechanical properties and flame retardancy of polypropylene using functionalized carbon nanotubes by covalently wrapping flame retardants followed by linking polypropylene. Mater Chem Front. 2017;1(4):716-26.

3. Wang JS, Wang GH, Liu Y, Jiao YH, Liu D. Thermal stability, combustion behavior, and toxic gases in fire effluents of an intumescent flame-retarded polypropylene system. Ind Eng Chem Res. 2014;53(17):6978-84.

4. Idumah CI, Hassan A, Bourbigot S. Synergistic effect of exfoliated graphene nanoplatelets and non-halogen flame retardants on flame retardancy and thermal properties of kenaf flour-PP nanocomposites. J Therm Anal Calorim. 2018;134(3):1681-703.

5. Liu Y, Wang JS, Deng CL, Wang DY, Song YP, Wang YZ. The synergistic flame-retardant effect of O-MMT on the intumescent flame-retardant PP/CA/APP systems. Polym Adv Technol. 2010;21(11):789-96.

6. Tian NN, Wen X, Jiang ZW, Gong J, Wang YH, Xue J, et al. Synergistic effect between a novel char forming agent and ammonium polyphosphate on flame retardancy and thermal properties of polypropylene. Ind Eng Chem Res. 2013;52(32):10905-15.

7. Shao ZB, Deng C, Tan Y, Chen MJ, Chen L, Wang YZ. Flame retardation of polypropylene via a novel intumescent flame retardant: ethylenediamine-modified ammonium polyphosphate. Polym Degrad Stabil. 2014;106:88-96.

8. Deng CL, Du SL, Zhao J, Shen ZQ, Deng C, Wang YZ. An intumescent flame retardant polypropylene system with simultaneously improved flame retardancy and water resistance. Polym Degrad Stabil. 2014;108:97-107.

9. Wang CL, Wang ZJ, Li J. Synergistic effects of dual imidazolium polyoxometalates on intumescent flame retardant polypropylene. J Appl Polym Sci. 2017;134(44):9.

10. Camino G, Costa L, Martinasso G. Intumescent flame retardant systems. Polym Degrad Stabil. 1989;23(4):359-76.

11. Bourbigot S, Lebras M, Delobel R. Carbonization mechanisms resulting from intumescence association with the ammonium polyphosphate-pentaerythritol fire retardant system. Carbon. 1993;31(8):1219-30.

12. Tian NN, Wen X, Gong J, Ma L, Xue J, Tang T. Synthesis and characterization of a novel organophosphorus flame retardant and its application in polypropylene. Polym Adv Technol. 2013;24(7):653-9.

13. Xiao D, Li Z, Zhao XM, Gohs U, Wagenknecht U, Voit B, et al. Functional organoclay with high thermal stability and its synergistic effect on intumescent flame retardant polypropylene. Appl Clay Sci. 2017;143:192-8.

14. Lai XJ, Zeng XR, Li HQ, Liao F, Yin CY, Zhang HL. Synergistic effect of phosphorus-containing montmorillonite with intumescent flame retardant in polypropylene. J Macromol Sci Part B Phys. 2012;51(6):1186-98.

15. Feng CM, Zhang Y, Liu SW, Chi ZG, Xu JR. Synergistic effects of $4 \mathrm{~A}$ zeolite on the flame retardant properties and thermal stability of a novel halogen-free PP/IFR composite. Polym Adv Technol. 2013;24(5):478-86.

16. Dong X, Nie SB, Liu ZG, Wang DY. Study of the synergistic effect of nickel phosphate nanotubes (NiPO-NT) on intumescent flame retardant polypropylene composites. J Therm Anal Calorim. 2016;126(3):1323-30. 
17. Yuan BH, Fan A, Yang M, Chen XF, Hu Y, Bao CL, et al. The effects of graphene on the flammability and fire behavior of intumescent flame retardant polypropylene composites at different flame scenarios. Polym Degrad Stabil. 2017;143:42-56.

18. Wang X, Sporer Y, Leuteritz A, Kuehnert I, Wagenknecht U, Heinrich $\mathrm{G}$, et al. Comparative study of the synergistic effect of binary and ternary LDH with intumescent flame retardant on the properties of polypropylene composites. RSC Adv. 2015;5(96):78979-85.

19. Qin ZL, Li DH, Li Q, Yang RJ. Effect of nano-aluminum hydroxide on mechanical properties, flame retardancy and combustion behavior of intumescent flame retarded polypropylene. Mater Des. 2016;89:988-95.

20. Feng CM, Zhang Y, Liang D, Liu SW, Chi ZG, Xu JR. Flame retardancy and thermal degradation behaviors of polypropylene composites with novel intumescent flame retardant and manganese dioxide. J Anal Appl Pyrolysis. 2013;104:59-67.

21. Ma ZL, Fan CR, Lu GY, Liu XY, Zhang H. Synergy of magnesium and calcium oxides in intumescent flame-retarded polypropylene. J Appl Polym Sci. 2012;125(5):3567-74.

22. Xu MJ, Wang J, Ding YH, Li B. Synergistic effects of aluminum hypophosphite on intumescent flame retardant polypropylene system. Chin J Polym Sci. 2015;33(2):318-28.

23. Shen YL, Gong WG, Zheng BC, Meng X, Gao L. Synergistic effect of Ni-based bimetallic catalyst with intumescent flame retardant on flame retardancy and thermal stability of polypropylene. Polym Degrad Stabil. 2016;129:114-24.

24. Li N, Xia Y, Mao ZW, Wang L, Guan Y, Zheng AN. Influence of antimony oxide on flammability of polypropylene/intumescent flame retardant system. Polym Degrad Stabil. 2012;97(9):1737-44.

25. Wen X, Wang YJ, Gong J, Liu J, Tian NN, Wang YH, et al. Thermal and flammability properties of polypropylene/carbon black nanocomposites. Polym Degrad Stabil. 2012;97(5):793-801.

26. Wu N, Yang RJ, Hao JW, Liu GS. Synergistic effect of metal oxides on intumescent flame-retardant pp systems. Acta Polym Sin. 2009;12:1205-10.

27. Yang HF, Gong J, Wen X, Xue J, Chen Q, Jiang ZW, et al. Effect of carbon black on improving thermal stability, flame retardancy and electrical conductivity of polypropylene/carbon fiber composites. Compos Sci Technol. 2015;113:31-7.
28. Wen X, Tian NN, Gong J, Chen Q, Qi YL, Liu Z, et al. Effect of nanosized carbon black on thermal stability and flame retardancy of polypropylene/carbon nanotubes nanocomposites. Polym Adv Technol. 2013;24(11):971-7.

29. Suhailath K, Jayakrishnan P, Naufal B, Periyat P, Jasna VC, Ramesan MT. Synthesis by in situ-free radical polymerization, characterization, and properties of poly( $n$-butyl methacrylate)/ samarium-doped titanium dioxide nanoparticles composites. Adv Polym Technol. 2018;37(4):1114-23.

30. Zanetti M, Kashiwagi T, Falqui L, Camino G. Cone calorimeter combustion and gasification studies of polymer layered silicate nanocomposites. Chem Mater. 2002;14(2):881-7.

31. Wang DS, Wen X, Chen XC, Li YH, Mijowska E, Tang T. A novel stiffener skeleton strategy in catalytic carbonization system with enhanced carbon layer structure and improved fire retardancy. Compos Sci Technol. 2018;164:82-91.

32. Li YC, Huang XR, Zeng LJ, Li RF, Tian HF, Fu XW, et al. A review of the electrical and mechanical properties of carbon nanofiller-reinforced polymer composites. J Mater Sci. 2019;54(2):1036-76.

33. Chen JW, Cui XH, Sui KY, Zhu YT, Jiang W. Balance the electrical properties and mechanical properties of carbon black filled immiscible polymer blends with a double percolation structure. Compos Sci Technol. 2017;140:99-105.

34. Wang XM, Zhuang YG, Dong LS. Study of carbon black-filled poly(butylene succinate)/polylactide blend. J Appl Polym Sci. 2012;126(6):1876-84.

35. Brigandi PJ, Cogen JM, Reffner JR, Wolf CA, Pearson RA. Influence of carbon black and carbon nanotubes on the conductivity, morphology, and rheology of conductive ternary polymer blends. Polym Eng Sci. 2017;57(12):1329-39.

36. Suhailath K, Ramesan MT. Investigations on the structural, mechanical, thermal, and electrical properties of Ce-doped $\mathrm{TiO}_{2} /$ poly(n-butyl methacrylate) nanocomposites. J Therm Anal Calorim. 2019;135(4):2159-69.

37. Kuzmanovic M, Delva L, Mi DS, Martins CI, Cardon L, Ragaert K. Development of crystalline morphology and its relationship with mechanical properties of PP/PET microfibrillar composites containing POE and POE- $g$-MA. Polymers. 2018;10(3):17.

Publisher's Note Springer Nature remains neutral with regard to jurisdictional claims in published maps and institutional affiliations. 